\title{
As verdades de Leandro Vieira
}

\section{Claudia Saldanha ${ }^{1}$}

Resumo: Acompanhar a trajetória do artista Leandro Vieira é vivenciar uma sucessão de inovações e de práticas ousadas de grande sofisticação estética. Desde seu primeiro enredo para a Mangueira, em 2016, até esse último, Leandro vem se revelando como um dos mais relevantes e destacados artistas brasileiros. Mas Leandro, é bom deixar claro, faz um movimento contrário ao de outros artistas. Não sobe o morro pra buscar inspiração mas ocupa as ruas, avenidas e os museus da cidade com sua produção cada dia mais sofisticada e exuberante e a cada ano mais contemporânea.

Palavras-chave: Arte popular, carnaval, Mangueira, arte contemporânea, manifesto, ópera popular.

\begin{abstract}
To follow the trajectory of the artist Leandro Vieira is to experience a succession of innovations and daring practices of great aesthetic sophistication. From his first carnival for Mangueira, in 2016, until this last one, Leandro has revealed himself as one of the most relevant and outstanding Brazilian artists. But Leandro makes a different movement contrary to other artists. He does not seek inspiration in the communities but occupies the streets, avenues and Rio de Janeiro's museums with an each year more sophisticated and exuberant production.
\end{abstract}

Keywords: Popular art, carnival, Mangueira, contemporary art, popular opera, manifest

\footnotetext{
${ }^{1}$ Graduada em Artes pela PUC, Mestra em Artes Visuais pelo Pratt Institute, Nova York e Doutora em Artes Visuais pelo Instituto de Artes Visuais da UERJ, Rio de Janeiro. Professora de História da Arte da UERJ. Diretora do Paço Imperial. De 2008 a 2014, Diretora da Escola de Artes Visuais do Parque Lage. De 2003 a 2005, dirigiu a Divisão de Teoria e Pesquisa do Museu de Arte Contemporânea de Niterói. De 1993 a 2005 dirigiu a Divisão de Artes Visuais do Instituto Municipal de Arte e Cultura RioArte.
} 
Lygia Pape afirmou certa vez, em entrevista a Glória Ferreira, que Hélio Oiticica transformou seu trabalho depois que conheceu o samba e a Mangueira. Daí, segundo Pape, o uso recorrente de imagens e objetos coletados em suas visitas ao morro. A partir desse encontro com o carnaval da Mangueira, Hélio

descobriu um outro lado da vida. Até ali era apolíneo, trabalhava no ateliê com aquelas cores, aquelas teorias. De repente, entra em contato com o espaço dionisíaco mesmo e descobre assim o mundo, o corpo, a vida, o morro, o samba [...]. Tomou aulas particulares com o maior passista da Mangueira, o Miro, para poder participar dos desfiles [...] e começou a realizar uma série de novas experiências. Aí é que surge o Parangolé [...]. Hélio extrapola o conceito de obra, começa a negar a pintura, porque a pintura agora são fulgurações, são relampejos de cor, da cor sobre o corpo que a usa... Hélio usa suas vivências do morro, não ilustrando, não fazendo barracos, mas utiliza aquele negócio de pisar na água, pisar na lama, andar no escuro do morro, o chiado da pedra quando se pisa. (PAPE, 2002)

Segundo o crítico britânico Guy Brett, foi a experiência de viver na favela da Mangueira que produziu em Oiticica e Pape uma estética antibelas-artes e antiburguesa que se deleitava com a poesia imprevisível das ruas, dos terrenos baldios (BRETT, 1997).

Reler a entrevista de Lygia Pape hoje, depois de assistir ao último desfile da Mangueira com o enredo "A verdade vos fará livre", faz-nos pensar sobre o grande poder do samba e das escolas de samba sobre todos nós. $E$, nesse contexto, Leandro Vieira se destaca com uma notável capacidade de reflexão, criação e domínio sobre os efeitos de luz, cor e movimento dessa que é nossa grande ópera popular - manifestação autêntica que, segundo Guy Brett, "transcende barreiras intelectuais, assim como de classe e poder" (p. 228).

Acompanhar a trajetória de Leandro Vieira é vivenciar uma sucessão de inovações e de práticas ousadas de grande sofisticação estética. Desde seu primeiro enredo para a Mangueira, em 2016, até esse último, Leandro vem se revelando como um dos mais relevantes e destacados artistas brasileiros. E digo artista brasileiro e não carnavalesco para reivindicar uma aproximação de gêneros. Formado pela Escola de Belas Artes da Universidade Federal do Rio de Janeiro, Leandro pode conhecer profundamente a história da arte, em especial a obra de artistas contemporâneos brasileiros. Na universidade foi treinado a lidar com tintas e pincéis e todos os recursos que uma escola de artes dispõe, além das discussões e reflexões sobre arte. 
Conheci Leandro Vieira durante a montagem de sua exposição no Paço Imperial, em 2016. Era o ano em que a Mangueira homenageava Maria Bethânia com o enredo "A menina dos olhos de Oyá". Acabara o Carnaval e Leandro havia conquistado seu primeiro título à frente de uma grande escola de samba do Grupo Especial do Rio de Janeiro. Ao entrar no Paço para conhecer a galeria onde iria expor, Leandro me disse que queria ser artista contemporâneo, que gostaria de fazer coisas, esculturas suas, sem vínculo com o Carnaval. Envolvidos com a urgência da exposição, não tivemos a chance de continuar a conversa.

Diante da falta de recursos prometidos, Leandro propôs uma montagem simples que estabelecia um diálogo de afeto com o público. Algo como um diário de bordo que mostrava o desenvolvimento da criação e execução de fantasias, adereços e carros alegóricos - período que durava nove meses. Em painéis adesivados nas paredes da galeria, contava como a escola de samba fazia escolhas e tomava decisões, muitas vezes resultado de uma criação coletiva. O mais significativo, entretanto, estava nas vitrines - desenhos preparatórios do artista para cada traje, destaque e adereço. O traço firme e vigoroso mostrava um pleno conhecimento da relação que cores e seus matizes provocam na retina. Anteviam os efeitos resultantes sob a luz da Sapucaí e propunham contrastes e semelhanças de formas e texturas. Ao lado de cada desenho, pedacinhos de tecidos definiam possibilidades para o efeito desejado. Era o Carnaval da Mangueira instalado no local que já recebeu Lygia Pape, Hélio Oiticica, Carlos Vergara e tantos outros. Centro cultural que, por improviso, fora Casa da Moeda e sede da família real na chegada de Portugal.

O novo enredo sobre Jesus que invadiu a avenida neste ano de 2020 "reconta a história de Jesus", "mostra todas as formas de Jesus: Jesus negro, Jesus menino com o cabelo descolorido, Jesus gay, Jesus mulher" revela para todos, segundo Leandro, a verdadeira história do homem pobre que viveu na Galileia. Ao exibir uma passista que interpreta Jesus mulher, com chagas no corpo vagando pela avenida e renunciando ao samba, Leandro subverte a tradição e apresenta seu Jesus de muitas caras, que apanha da polícia na comissão de frente e que se transveste em múltiplas faces, quase tantas quanto as que existem nas ruas da cidade. E, acompanhando o desfile, representantes de todos os credos, líderes espirituais das crenças que formam o país, mostram seu apoio.

A Mangueira sempre representou a raiz do samba, é a escola de Cartola, de Nelson Sargento, de Beth Carvalho. Como pode abdicar de seu papel de escola maior, escola tradicional e uma das mais queridas do povo? 
Com componentes da bateria vestidos de mulher, em 2017, uma portabandeira de cabeça raspada, em 2018, e uma madrinha de bateria que atravessa a avenida sem o samba no pé, em 2020, a Mangueira mudou, revolucionou seu desfile e as relações entre seus componentes. Hoje há nela um discurso, uma reflexão, uma performance moderna. Ali misturam-se música, ritmo, arte, corpo e dança como poucas vezes podemos presenciar.

A "maior improvisação pública do mundo" transforma-se assim, em poucos instantes, em uma grande obra de Leandro Vieira, a desfiar pela avenida sua vitalidade e sua contemporaneidade, suas preces em tom de denúncia, seus apelos para a tolerância com os mais fracos, com os diferentes, com os oprimidos sem pieguice, quase em tom de escárnio, exibindo em forma de chagas aquilo que a miséria e a opressão podem provocar. O samba da Mangueira é um manifesto, o desfile é uma narrativa que deflagra em todos a reflexão sobre as profundas modificações pelas quais estamos passando, em especial o agravamento da intolerância religiosa e da violência social. Está aí uma escola de samba muito além do seu tempo, que se reinventa a cada ano pelas mãos de Leandro Vieira!

Mário Pedrosa dizia que "a arte popular nunca participou das honras da historiografia da arte erudita, capítulo da grande história das nações do mundo ocidental" (PEDROSA, 1995). Chamava atenção para a perigosa mitificação, por parte de políticos e teóricos do artesanato popular como fonte mais autêntica da cultura popular:

Nem sempre ele significa uma forma criadora do povo que signifique uma posição revolucionária. Pelo contrário, nele se expressa a ideologia da dependência, na medida em que é uma produção destinada a atender o interesse pelo folclórico do mercado turístico. Esse interesse é o reflexo da imagem colonizadora que os países capitalistas impõem à nossa América.

Mário não viveu para ver os grandes nomes do Carnaval. E não assistiu às transformações pelas quais a arte, seja ela "popular", "erudita", ou mesmo a arte das ruas e das comunidades vem passando. Não pode testemunhar essa grande mistura de cultura de inspiração popular que explode nas quadras das escolas, nos morros e nas avenidas.

Se aqui estivesse, se encontrasse Leandro Viera e conhecesse os enredos da Mangueira "A menina dos olhos de Oyá" (2016), "Só com a ajuda do santo" (2017), "Com dinheiro ou sem dinheiro eu brinco" (2018), "História para ninar gente grande" (2019) e "A verdade vos fará livre" (2020), escreveria sobre o atravessamento de culturas e a 
contemporaneidade da arte produzida por Leandro e, muito provavelmente, enalteceria sua produção artística e o alçaria ao patamar de Pape e Oiticica. Mas Leandro, é bom deixar claro, faz um movimento contrário - não é artista que sobe o morro pra buscar inspiração, mas é aquele que desce o morro, ocupa as ruas, avenidas e os museus da cidade com sua produção cada dia mais sofisticada e exuberante e a cada ano mais contemporânea.

Em depoimento sobre sua atuação na escola Imperatriz Leopoldinense este ano, com enredo sobre Lamartine Babo Leandro afirmou: "Sou um artista contemporâneo e olho para ele [Babo] com um olhar contemporâneo. Tenho o cuidado de adaptar isso aos novos tempos, sobretudo no discurso estético".

\section{Referências}

BRETT, Guy. O exercício experimental da liberdade. Hélio Oiticica (catálogo). Rio de Janeiro: Centro de Arte Hélio Oiticica, 1997.

PAPE, Lygia. Lygia Pape (catálogo). Rio de Janeiro: Centro de Arte Hélio Oiticica, 2002.

PEDROSA, Mário. Arte Culta e Arte Popular. In: Arantes, Otília (org.). Política das Artes. São Paulo: Edusp, 1995. p. 321-332. 